\title{
ROAD: Interactive Geometric Design Tool for Transportation Education and Training
}

\author{
Chen-Fu Liao ${ }^{1}$ and David M. Levinson, Ph.D. ${ }^{2}$
}

\begin{abstract}
Traditionally, transportation engineering students have used engineering drawing techniques to manually lay out lines and curves over contour maps for highway geometric design. The design process requires numerous calculations of stopping sight distance, minimum turning radius, and curve alignments to minimize economic and environmental impact and construction costs. Students usually perform iterative computations to manually meet design criteria and environmental constraints. The traditional approach of learning geometric design is cumbersome and time consuming, limiting students from taking a broader perspective on geometric design. A new software tool, Roadway Online Application for Design (ROAD), was developed to enhance the learning experience for transportation engineering students. This tool allows students to design roadway geometry efficiently and modify the design easily within given economic and environmental parameters. The objective is to provide a comprehensive tool that can be accessed easily by students in order to help them better understand geometric design. ROAD can also generate a three-dimensional roadway geometry model at final design to allow students to place themselves in the driver's seat and maneuver through the designed roadway at maximum design speed. DOI: 10.1061/(ASCE)EI.1943-5541 .0000142. (ㅇ 2013 American Society of Civil Engineers.
\end{abstract}

CE Database subject headings: Geometry; Design; Highways and roads; Engineering education; Training; Transportation engineering.

Author keywords: Geometric design; Distance learning; Transportation visualization.

\section{Introduction}

An introductory transportation engineering course is usually required in undergraduate civil engineering programs. Due to time constraints and numerous transportation topics, the focus of the introductory course depends on the instructor's area of expertise. Beyerlein et al. (2010) raised the need for national collaboration and content coordination in teaching transportation engineering. Kyte (2009) brought together university faculty and transportation professionals in a transportation education conference to focus on this issue and to identify ways to improve undergraduate transportation engineering education. As a collaborative effort of several university faculty members, core learning outcomes and knowledge tables have been identified as critical to introducing transportation engineering to undergraduate civil engineering students (Bill et al. 2011). Survey results from civil engineering practitioners suggest that highway geometric design is one of the most important topics for introductory transportation engineering courses (Khisty 1986; Turochy 2006).

The design of modern roadways is a sophisticated process that presents the highway engineer with many challenges. A roadway designer often has to consider several design controls and

\footnotetext{
${ }^{1}$ Senior Systems Engineer, Minnesota Traffic Observatory, Dept. of Civil Engineering, Univ. of Minnesota, 500 Pillsbury Dr. SE, Minneapolis, MN 55455 (corresponding author). E-mail: cliao@umn .edu

${ }^{2}$ Professor and RP Braun/CTS Chair in Transportation Engineering, Dept. of Civil Engineering, Univ. of Minnesota, 500 Pillsbury Dr. SE, Minneapolis, MN 55455. E-mail: dlevinson@umn.edu

Note. This manuscript was submitted on May 2, 2012; approved on October 9, 2012; published online on October 11, 2012. Discussion period open until September 1, 2013; separate discussions must be submitted for individual papers. This paper is part of the Journal of Professional Issues in Engineering Education \& Practice, Vol. 139, No. 2, April 1, 2013. (C) ASCE, ISSN 1052-3928/2013/2-116-122/\$25.00.
}

criteria that go beyond the basic application of regulatory standards. Traffic changes, construction costs, real estate prices, vehicle differences, and environmental and ecological considerations are all challenges that civil engineers face. A properly designed roadway takes into consideration mobility and safety issues while addressing economic impacts and environmental constraints (Mannering et al. 2005).

Among the geometric elements involved in roadway design, alignment is the most important component. Detailed guidelines of geometric design are discussed in AASHTO (2011).

Traditionally, students have used engineering drawing techniques to design roadway geometry over contour maps. Calculations of stopping sight distance, minimum turning radius, and curve alignments are conducted during the geometric design process in order to ensure safety and compliance with design guidelines aimed to produce consistent driver expectations and operations, to minimize economic and environmental impacts, and to reduce construction costs. In an introductory geometric design curriculum, students usually perform iterative calculations manually during the design process to meet certain design criteria and environmental constraints.

The traditional process of geometric design is often cumbersome and time consuming. It limits students from considering the overall design process from a broader perspective. Many commercial software packages used professionally were developed by incorporating active digital maps, three-dimensional (3D) design models, and virtual reality walkthroughs to enhance the intelligence and connectivity for roadway design and planning process (ITS International 2006). The commercial tools are usually complicated and expensive and thus, inappropriate for classroom use. The development work of the educational software does not intend to duplicate or even compete with the commercial packages. The goal is to provide a simple web-based tool with necessary features that allow students to better understand the process of geometric design without climbing a steep learning curve. 
An Internet-based geometric design software package called Roadway Online Application for Design (ROAD) was developed using the Java programming language with the objective of helping students better understand the roadway planning and design process. ROAD assists students in conducting geometric design on a computer screen with an imported digital contour map as the graphical design reference in the background. Students are able to design the geometry of a roadway more effectively and thereafter can focus more on strategic decisions, transportation planning, and potential environmental and economic impacts. Furthermore, the final geometric design can be visualized in a $3 \mathrm{D}$ virtual reality environment using Virtual Reality Model Language (VRML) (Ames et al. 1997) on a web browser to examine the final roadway design from different perspectives.

\section{Web-Based Geometric Design}

In recent years, web-based education has become a popular and effective way of complementing classroom instruction. Online learning tools bring the classroom laboratory to students on their computers. Web-based learning tools offer the benefit of platform and location independence. Users can virtually access the learning tool anytime and anywhere around the world using computers with Internet access.

Clearly, this approach can be integrated with other distance learning approaches already in place for teaching transportation technologies. For example, Liao et al. (2006) developed a webbased traffic simulation framework for transportation training and education. Several web research modules and games were developed by the ITS Institute at the University of Minnesota for high school students (Liao et al. 2010). Chen and Levinson (2006) investigated the efficacy of using an online simulation tool in teaching the topic of transportation network growth, conducted in a senior/graduate class in transportation system analysis, showing that the use of online simulation tool enhanced students' learning. Liao et al. (2009) developed a suite of web-based simulation modules, and Kyte et al. (2003) used hands-on workshops to improve and enrich curriculum in teaching introductory level of transportation engineering course as part of undergraduate civil engineering programs. Zhu et al. (2011) developed an agent-based travel demand model. Helbing et al. (2002) developed freeway traffic models to help people better understand on-ramp vehicle merging, lane changing, car following, lane closing, and signal control through online traffic simulation and visualization (Treiber 2010).

\section{Approach}

The initial development of ROAD focuses on the geometric design components and criteria. A digital contour map is used as a reference image in the background for students to lay out the roadway. The web-based tool provides ease of design and modification of construction lines and horizontal and vertical curves. It also allows students to place the roadway construction line/curve at an appropriate location with respect to the contour map and other environmental constraints. Vertical design includes the additional capability of adjusting point of vertical curve intersect (PVI) in order to minimize earth cutting or filling. The roadway design software tool automatically generates design reports and mass diagrams for earthwork estimation. ROAD also includes features to allow users to save or load horizontal and vertical design separately. More detailed instructions on using ROAD are available online in the ROAD User's Manual [Minnesota Traffic Observatory (MTO) et al. 2008].

\section{Horizontal Geometric Design}

After a digital contour image is imported as background in ROAD, information regarding the image resolution and map scale can be specified in the design settings screen as shown in Fig. 1(a). Other design criteria such as speed limit, maximum cut and fill, maximum grade, driver reaction time, minimum curve length, minimum curve radius, and others [Fig. 1(b)] can be specified before beginning roadway design. The driver reaction time is used to compute the stopping sight distance. After specifying the design parameters and map scale, students can use the line construction tool from the toolbar to lay out the draft roadway design by following the direction tangent to existing contour curves. This helps the designer reduce the amount of earth cut and fill along the proposed roadway design. A roadway cutting through relatively steep elevation region is likely to be more expensive to construct.

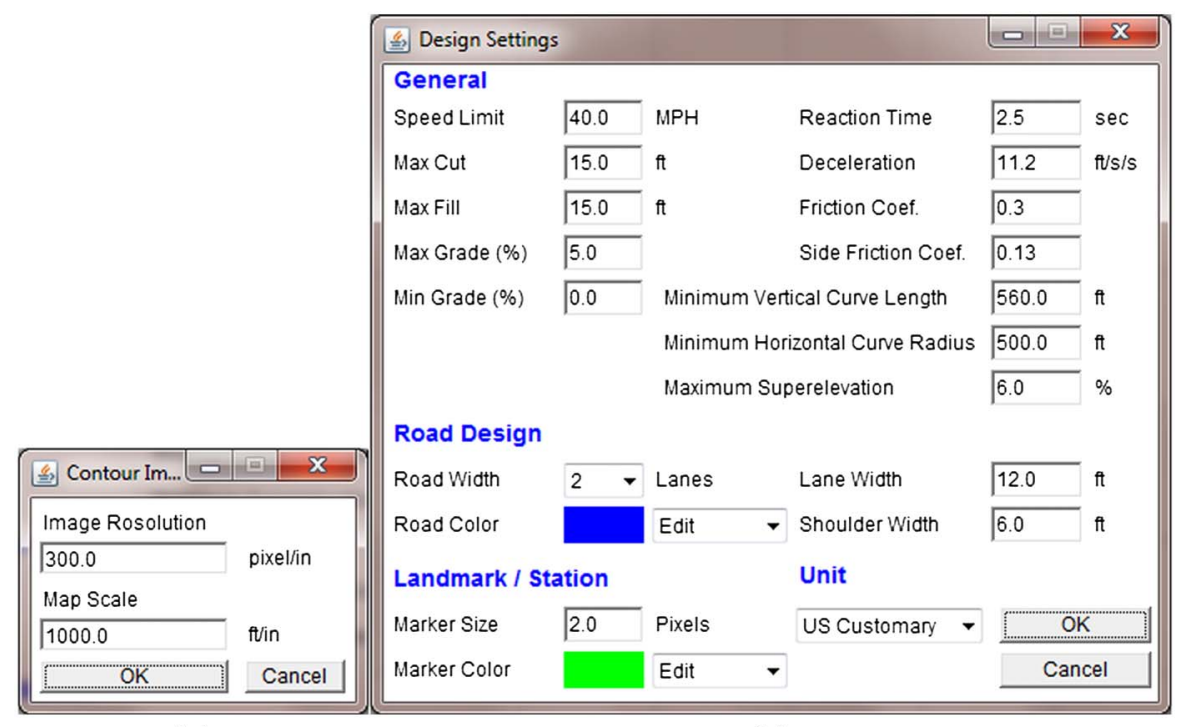

(a)

(b)

Fig. 1. (a) Map and image settings; (b) roadway geometry design settings 
For example, suppose an engineer would like to design a twolane roadway from Point $\mathrm{C}$ to Point $\mathrm{D}$, as illustrated in Fig. 2. Horizontal construction line segments are generated by clicking on a desired starting location over the contour map and then dragging the mouse to a desired ending location. Endpoints of linear segments can later be modified using the editing tool for further adjustment. A curve segment can also be generated by using the curve construction tool with desired curve radius. Users can check the minimum curve radius requirement based on the design speed and maximum grade of the roadway. The newly created curve segment can thereafter be placed inside two crossover lines (Fig. 2) as a curve transition between two linear segments. The curve segment does not need to be placed exactly tangent to both lines initially. By selecting two crossover linear segments and a nearby curve, users can use the alignment tool under the option menu (or from the toolbar) to automatically calculate the tangent points and adjust the curve segment tangent to both adjacent linear segments. Spiral transition curves are not currently implemented.

In general, the major considerations in horizontal alignment design include safety, type of facility, design speed, topography, and construction cost. In geometric design, safety is always considered, either directly or indirectly. Topography controls both curve radius and design speed to a large extent. The design speed, in turn, controls sight distance, but sight distance must be considered concurrently with topography because it often demands a larger radius than the design speed. All these factors must be balanced to produce an alignment that is safe, economical, in harmony with the natural contour of the land, and, at the same time, adequate for the design classification of the roadway or highway (AASHTO 2011). The iterative design process becomes tedious and cumbersome when using the traditional approach.

Currently, the elevation information is displayed on the contour map but not digitally available from the image file. Using the station/landmark tool, students can sequentially create landmark stations at every location where the contour curve intersects with the proposed roadway segment. Elevation of each tangent point, where transition occurs between the line and curve segments, should also be included as a transition landmark between the line and curve segment. Elevation information at each station must be entered or interpolated according to the nearby elevation of the contour curves. Location and elevation information of selected stations can be listed by clicking on the view/station landmarks tool. Students need to specify the elevation information of each station sequentially in the horizontal design to prepare data for the vertical curve design. Both insert and edit tools are available for users to insert a new landmark or modify the elevation from existing landmark station.

\section{Vertical Curve Design}

After the horizontal geometric design is completed, vertical curve design is performed to ensure continuous grade variation for safety and driving comfort. The elevation information of each station is plotted versus the calculated horizontal road distance from the starting to the end station according to the roadway trajectory in horizontal design as discussed in the previous section. An elevation profile for the vertical design is illustrated in Fig. 3 as an example. Users can lay out the construction lines for the vertical curve design with the vertical curve construction tool. Preliminary construction lines usually begin at the starting station by clicking on the first landmark (at zero distance) on the graph (Fig. 3). Users can then move the mouse and sequentially click on the desired point of vertical intersection (PVI) over the elevation profile until reaching the end station by double-clicking the last landmark (or using the end construction icon from the toolbar). After completing the preliminary vertical construction lines, students can drag the PVI point to adjust the preliminary construction lines. Students can visually balance potential cut and fill through the adjustment of the PVI points initially. Students can then use the vertical curve calculation tool to compute the point of vertical curvature (PVC) and the point of vertical tangency (PVT) of each vertical curve. The PVC, PVT, and PVI points are calculated automatically by the software and labeled with different markers (square, diamond, triangle), as displayed in Fig. 3. ROAD calculates the stopping sight distance and curve length using the formulas suggested in the AASHTO

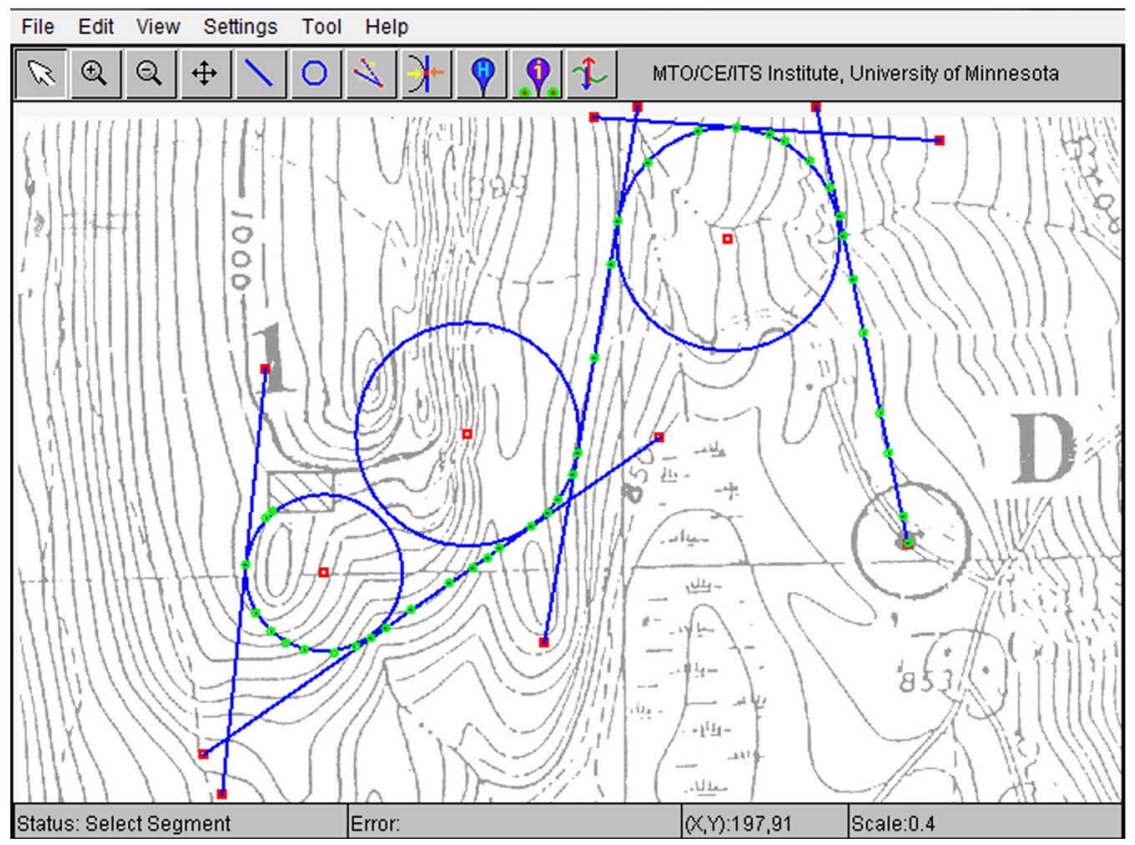

Fig. 2. Horizontal geometry design 


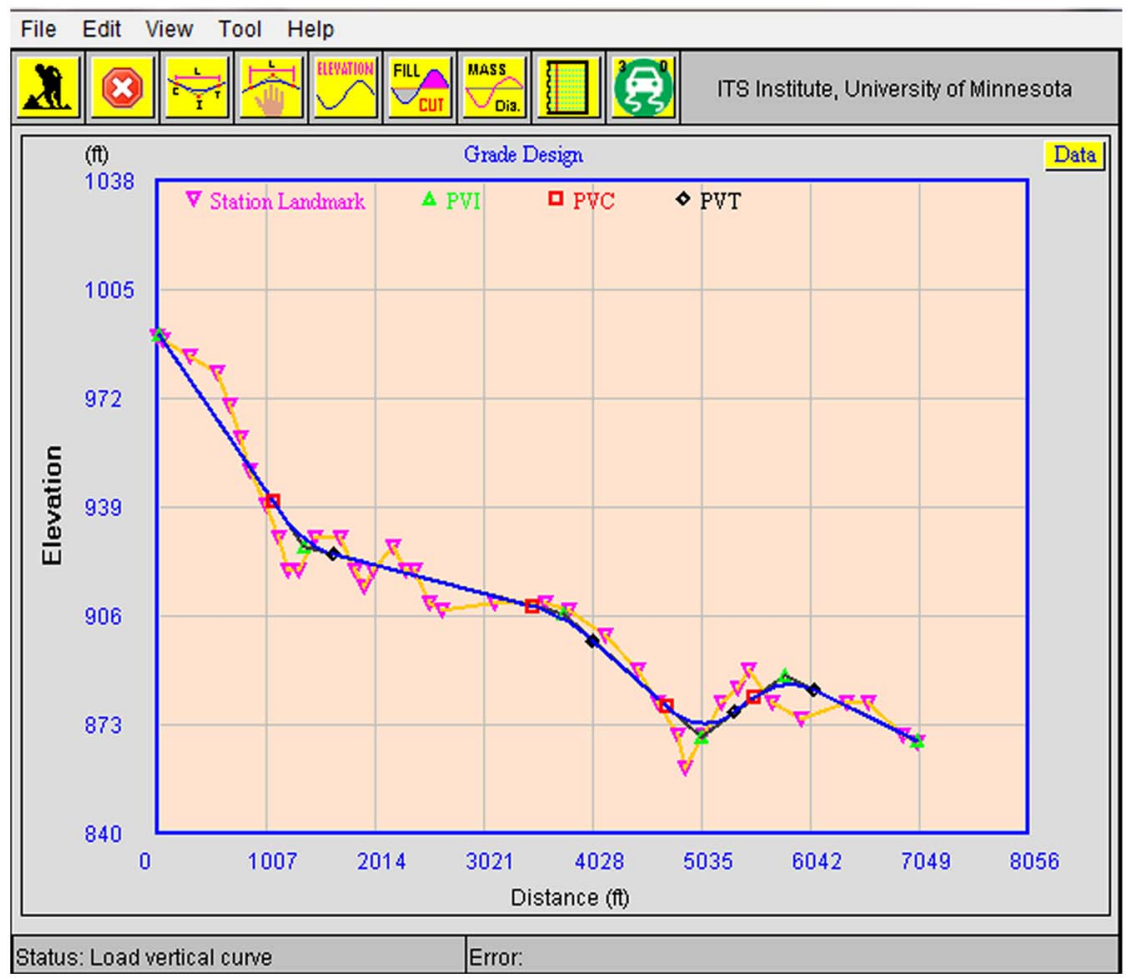

Fig. 3. Vertical curve design-elevation profile

design manual. The curve length of each vertical curve can also be modified individually using the curve edit tool from the toolbar.

After the vertical curve design is performed, the cut-and-fill profile based on the designed vertical curve can also be calculated and plotted by clicking on the fill/cut icon from the toolbar, as shown in Fig. 4. The zero horizontal line in the cut-and-fill profile graph represents the elevation of the proposed vertical curve design. Line segments above zero imply that the actual elevation is higher than the designed vertical curve. This will require earth removal. The segments below zero require additional earth fill. Maximum cut-and-fill constraints initially specified in the design settings screen are also plotted as references. When maximum

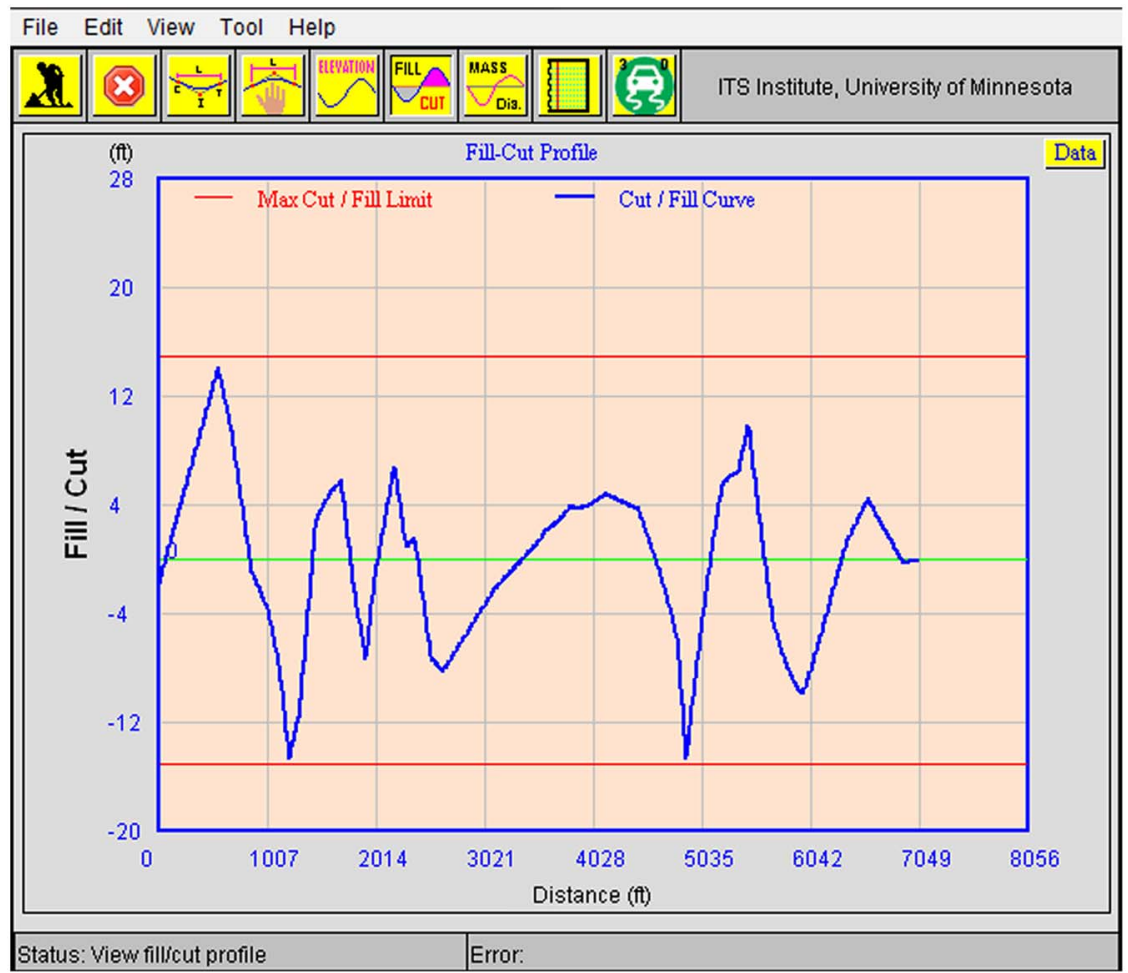

Fig. 4. Vertical curve design-fill-and-cut profile 
cut/fill constraints are not met, users can visually identify the location that exceeds cut/fill constraints from the cut-and-fill profile, go back to the elevation profile, clear the designed vertical curve using the clear curves tool under the edit menu, and then adjust the vertical curve by modifying the PVI points of the vertical curve construction lines in the elevation profile. If cut-and-fill design criteria cannot be met by merely adjusting the vertical PVI points, then students may need to redesign the vertical profile by using the clear design function under the edit menu to remove both vertical curves and construction lines. If students still cannot perform vertical curve design within the maximum grade and cut and fill requirements, then they may need to redesign the horizontal curves with better horizontal route selections. This iterative process may repeat many times before a solution is found that can satisfy all of the design requirements.

A mass diagram of the roadway design is available to estimate the amount of earthwork required along the proposed roadway construction. The final design report, as shown in Fig. 5, which includes the station location and elevation information, grade, and amount of total earthwork, can be generated automatically by the software after the final geometric design is complete.

\section{D Animation}

A 3D roadway geometry model can be generated by ROAD based on the geometric data from the horizontal trajectory and the elevation data from the vertical curve design using VRML. A VRML client (plug-in) is required to render the animation of the 3D roadway design.

Virtual reality (VR) models and animation have been widely used in classrooms to enhance student learning (Pantelidis 1995). VR offers many benefits such as allowing observation from a great distance, close-up examination, and providing students opportunities for insights. Traditionally, transportation engineering students validate their final geometric design by verifying their calculations to ensure all design criteria are met. They do not have the

\begin{tabular}{|c|c|}
\hline File & \\
\hline Roadway Geometry Design Report & $\hat{a}$ \\
\hline Vertical Curve Design Summary & \\
\hline Total road length $=7520.867 \mathrm{ft}=1.4244066$ miles. & \\
\hline Grade $(1)=-4.8533707 \%$ & \\
\hline Grade $(2)=-0.8479098 \%$ & \\
\hline Grade $(3)=-2.932109 \%$ & \\
\hline Grade $(4)=2.4221773 \%$ & \\
\hline Grade $(5)=-1.6160833 \%$ & $\equiv$ \\
\hline Curves Location and Elevation & \\
\hline Curve(1) Length $=592.3356 \mathrm{ft}$ & \\
\hline PVC $($ distance, elevation $)=(1047.1145,940.6894) \mathrm{ft}$ & \\
\hline PVI (dist_prj, elevation) $=(1359.4501,927.1) \mathrm{ft}$ & \\
\hline PVT $($ distance, elevation $)=(1639.4501,924.7258) \mathrm{ft}$ & \\
\hline Min. elevation $($ distance, elevation $)=(1639.4501,924.72577) \mathrm{ft}$ & \\
\hline Curve (2) Length $=602.0049 \mathrm{ft}$ & \\
\hline PVC $($ distance, elevation) $=(3437.462,909.12415) \mathrm{ft}$ & \\
\hline PVI (dist_prj, elevation) $=(3759.4668,906.75) \mathrm{ft}$ & \\
\hline $\mathrm{PVT}$ (distance, elevation) $=(4039.4668,898.5401) \mathrm{ft}$ & \\
\hline Max. elevation (distance, elevation) $=(3479.4668,909.12415) \mathrm{ft}$ & \\
\hline Curve(3) Length $=679.60596 \mathrm{ft}$ & \\
\hline PVC (distance, elevation) $=(4669.394,878.5568) \mathrm{ft}$ & \\
\hline PVI (dist_prj, elevation) $=(5035.0,869.35) \mathrm{ft}$ & \\
\hline PVT $($ distance, elevation $)=(5349.0,876.9556) \mathrm{ft}$ & \\
\hline Min. elevation $($ distance, elevation $)=(5064.905,873.51495) \mathrm{ft}$ & \\
\hline Curve $(4)$ Length $=621.44775 \mathrm{ft}$ & \\
\hline PVC $($ distance, elevation $)=(5465.5854,881.2679) \mathrm{ft}$ & \\
\hline PVI (dist_prj. elevation) $=(5807.033,888.05) \mathrm{ft}$ & \\
\hline PVT $($ distance, elevation $)=(6087.033,883.52496) \mathrm{ft}$ & \\
\hline Max. elevation $($ distance, elevation $)=(5862.9253,885.3359) \mathrm{ft}$ & - \\
\hline 1 & \\
\hline
\end{tabular}

Fig. 5. Report of roadway geometry design

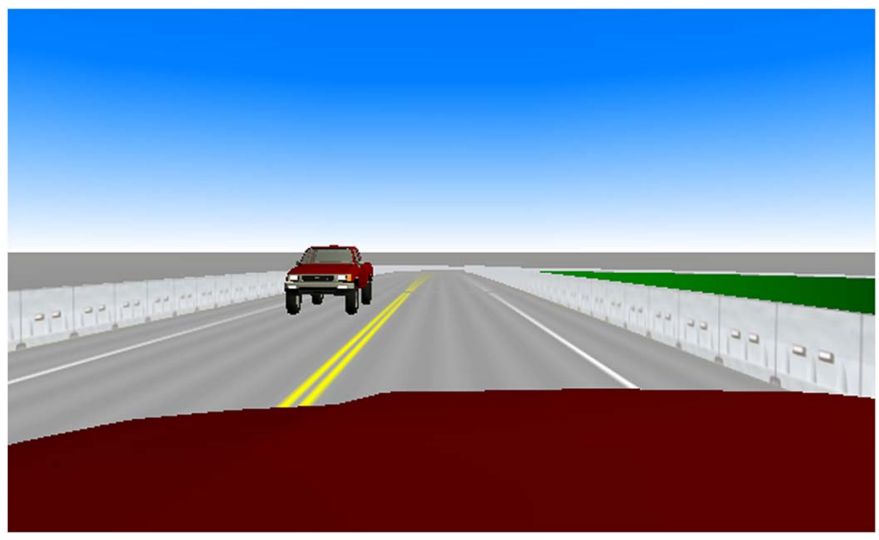

Fig. 6. Drive-through animation

opportunity to visualize or examine the final roadway design through a 3D model/animation. Generating a 3D roadway model in a VR environment allows students to examine their design and experience potential sight distance issues that may not appear in separate calculations of horizontal and vertical design. In the 3D view, as illustrated in Fig. 6, students can place themselves in the driver's seat and drive through their roadway design from a driver's perspective at maximum design speed. The $3 \mathrm{D}$ animation provides an invaluable opportunity for students to evaluate sight distance and potential safety concerns. Furthermore, the 3D roadway model can be exported to a driving simulator (ITS Institute 2010) for further study on road safety and driver responses.

\section{Deployment}

ROAD was deployed as a lab module in undergraduate civil engineering class CE3201, "Introduction to Transportation Engineering" (a three-credit course in a 15-week semester including $1 \mathrm{~h} /$ week lab), since 2006 at the University of Minnesota. An online user's manual and help documentation are available to students. Prior to the geometric design lab assignment, students were given a homework exercise to design a single-curve roadway geometry using the traditional approach. The homework exercise aimed to ensure students understood the design process, equations, and calculations without the assistance of the computer software. A digital contour map was provided to students for a two-lane highway design connecting a visitor center at location Point 1 on the map to the existing road network using ROAD. Two potential access points were proposed, Points B and E on the map. Students were asked to design and recommend a route connecting the visitor center to the existing road network through either Location B or E. Alignment parameters and other design criteria, as previously shown in Fig. 1(b), were also provided to students for the geometric design. Students were divided into groups for the design project. Each group consisted of two or three people. Each group was asked to submit a short report (two to three pages) describing their design including the horizontal alignments, vertical alignments, and results.

\section{Evaluation and Results}

At the beginning of the lab assignment, a 1-h tutorial was given to students on how to use ROAD. Students had about 5 weeks to work on their design as a group in the civil engineering computer lab or from their PC at home. After learning the software tool ( $2 \mathrm{~h}$ on average), students spent about $3-5 \mathrm{~h}$ to finish the project. 
Table 1. List of Survey Questions and Results

\begin{tabular}{|c|c|c|c|c|}
\hline Number & Question & Response criteria & Average score & Standard deviation \\
\hline 1 & How interesting did you find ROAD to use? & $\begin{array}{l}\text { Dull (1) } \\
\text { Stimulating (5) }\end{array}$ & 3.19 & 1.24 \\
\hline 2 & ROAD interface & $\begin{array}{l}\text { Unpleasant (1) } \\
\text { Pleasant (5) }\end{array}$ & 3.04 & 1.16 \\
\hline 3 & Organization of information & $\begin{array}{l}\text { Confusing }(1) \\
\text { Clear }(5)\end{array}$ & 3.47 & 1.12 \\
\hline 4 & Supporting information for lab assignment(s) was clear & $\begin{array}{l}\text { Strongly disagree (1) } \\
\text { Strongly agree }(5)\end{array}$ & 3.33 & 1.07 \\
\hline 5 & There was sufficient supporting information & $\begin{array}{l}\text { Strongly disagree (1) } \\
\text { Strongly agree }(5)\end{array}$ & 3.33 & 1.04 \\
\hline 6 & $\begin{array}{l}\text { Use of ROAD provided opportunities to practice skills } \\
\text { learned in lecture part of course }\end{array}$ & $\begin{array}{l}\text { Strongly disagree }(1) \\
\text { Strongly agree }(5)\end{array}$ & 3.47 & 1.22 \\
\hline 7 & $\begin{array}{l}\text { Learning was enhanced through practical experiences } \\
\text { ("doing") provided in assignment }\end{array}$ & $\begin{array}{l}\text { Strongly disagree (1) } \\
\text { Strongly agree }(5)\end{array}$ & 3.60 & 1.06 \\
\hline 8 & Interactive approach applied in ROAD enhanced learning & $\begin{array}{l}\text { Strongly disagree (1) } \\
\text { Strongly agree }(5)\end{array}$ & 3.50 & 1.12 \\
\hline 9 & I was motivated by teaching strategy using ROAD & $\begin{array}{l}\text { Strongly disagree }(1) \\
\text { Strongly agree }(5)\end{array}$ & 3.26 & 1.14 \\
\hline 10 & Learning to use ROAD was easy & $\begin{array}{l}\text { Strongly disagree (1) } \\
\text { Strongly agree }(5)\end{array}$ & 3.40 & 1.31 \\
\hline 11 & Quality of ROAD as a learning tool & $\begin{array}{l}\text { Poor (1) } \\
\text { Very high }(5)\end{array}$ & 3.43 & 1.10 \\
\hline 12 & Overall learning experience with ROAD & $\begin{array}{l}\text { Poor (1) } \\
\text { Great (5) }\end{array}$ & 3.32 & 1.10 \\
\hline 13 & Overall satisfaction with ROAD & $\begin{array}{l}\text { Low (1) } \\
\text { High (5) }\end{array}$ & 3.07 & 1.16 \\
\hline
\end{tabular}

To evaluate the effectiveness of ROAD, a survey was conducted in class after students turned in their project reports. An online survey was set up to facilitate the process of collecting students' feedback in 2009. Over the past few years, the authors have collected 106 paper results and 77 online responses from students. A list of survey questions, average score, and standard deviation are displayed in Table 1. Regarding student demographic information, $81 \%$ of the respondents were male and the others were female. Most students were juniors (57\%), 25\% were seniors, and $12 \%$ were sophomores.

Overall, the students are motivated $(3.26 / 5)$ and interested in using ROAD $(3.19 / 5)$, the interface is moderately pleasant (3.04/5), and the presented information is organized (3.47/5) with sufficient and clear information (3.33/5). Students like the opportunities and interactive approach to practice skills learned in the classroom (3.5/5) and report that their learning experiences are enhanced through the exercise (3.6/5). On average, ROAD provides acceptable learning quality (3.43/5) and is relatively easy to use (3.4/5). Students are moderately satisfied (3.07/5) and enjoy the learning experience $(3.32 / 5)$ with ROAD.

Some students commented that using the computer-aided tool for design made the project easier. Students' comments, such as "it made the project a lot easier and allowed us to try multiple designs much faster" and "it was much faster than doing it by hand," suggest the tool would help in learning the concepts of geometric design. The tool allows them to gain real design experience and a better understanding of roadway geometry. The solutions from pre-ROAD design projects were usually limited. Survey results indicated that ROAD helps students to explore various designs within given constraints and finish project assignments in a timely manner. Generally speaking, most students agreed that the CAD approach enhanced their learning experience of geometric design. A few students thought they would use AutoCAD software for the design prior to the project assignment. ROAD helps students better understand the design process and requirements of geometric design in a broader perspective, which includes roadway planning, safety, construction costs, and so on.

There were questions and suggestions from students regarding saving the design file and deleting/editing horizontal landmark stations. Both recommendations were incorporated into the latest revision of ROAD. Further usability testing of the graphical user interface (GUI) might be considered to improve ROAD.

As compared to the traditional engineering drawing approach, designing roadway geometry on screen is simpler. It is easier to edit compared to an iterative design process, according to students' comments from the survey. The tutorials and demos during lab sessions helped students begin. Based on survey recommendations, additional features were added that allow users to insert and edit horizontal landmark stations. A 1-h lab instruction session was provided to students at the beginning of the project assignment. According to feedback, some students would like to have more lab instruction (one more hour) to go through further detail that will help them finish the project more efficiently and effectively.

Online help documentation is embedded in ROAD. A PDF version of the user's manual is also available for download from the class website and now includes index search capabilities.

\section{Conclusion}

This paper introduces and evaluates the use of the highway geometric design package ROAD in a transportation engineering class. The online tool helps students better understand the different aspects of geometric design as compared to the traditional approach. The objective of incorporating ROAD into the teaching of geometric design is not to reduce or ignore the importance of the underlying equations, calculations, or theory. The goal is to help students better understand the challenges of geometric design that transportation engineer faces. 
Since fall 2006, a homework exercise has been assigned to students to design a single-curve roadway geometry by hand prior to the lab project. The exercise prepares students to understand the equations and calculations of geometric design and its process. To give students more time to familiarize themselves with ROAD, another exercise to redesign the same single-curve homework assignment using ROAD is recommended to instructors. This will provide us with a better comparison of the learning experience of roadway design using ROAD and the traditional approach. One of the instructional challenges is the class size (usually 60-70 students each semester) of the CE3201 class, which is a required undergraduate engineering class. Students are generally divided into three lab sessions. But more importantly, the instructional challenges come from students' motivation for taking this mandatory class. The authors hope that, through the assistance of ROAD and in-class tutorials, students can better understand the procedures that transportation professionals take in order to perform geometric design. And through the use of ROAD, students can explore different geometric designs that can satisfy given design constraints and requirements in real-world applications.

\section{Future Work}

Currently, a 2D contour image is used as background for geometric design. Elevation information at each station must be entered sequentially and manually. In the future, the authors plan to develop an interface to import digital terrain model (DTM) data. Elevation information can be extracted from the DTM automatically. The digital terrain model can also be integrated into the 3D animation model to enhance the realism of the drive-through experience and identify potential safety concerns at the final roadway design. Visualizing the final roadway design in 3D was optional in the class project. However, it offers an important verification and validation tool in a real-world roadway design application used by the professionals. The authors believe that by providing geometric design that incorporates visualization tools available on the Internet along with the ability to investigate and analyze different cause-and-effect scenarios, students will better understand the potential impact of their design.

ROAD will be available for future introductory transportation engineering and senior-level highway engineering classes. Further refinement and enhancement to the software will be made based on feedback from students and instructors. ROAD, together with other online transportation modules developed by the University of Minnesota, has been included in the Simulating Transportation for Realistic Engineering Education and Training (STREET 2012) project.

\section{Acknowledgments}

This material is based in part upon work supported by the National Science Foundation under Grant No. 0717504 titled "STREET: Simulating Transportation for Realistic Engineering Education and Training" and the Intelligent Transportation Systems (ITS) Institute, University of Minnesota, with funding from the U.S. Department of Transportation through the University Transportation Centers program. The authors would like to acknowledge the Digital Media Center and the Department of Civil Engineering at the University of Minnesota for supporting this work. The authors would like to thank Ted Morris at Minnesota Traffic Observatory for sharing his experience and comments from his previous involvement with traditional geometric design in a transportation engineering class. The authors would also like to thank the class instructors and teaching assistants for providing access to students and collecting feedback. The authors appreciate the support from the Center for Transportation Studies for setting up the online survey interfaces.

\section{References}

AASHTO. (2011). "Elements of design." Chapter 3, A policy on geometric design of highways and streets, 6th Ed., Federal Highway Administration (FHWA), Washington, DC.

Ames, A. L., Nadeau, D. R., and Moreland, J. L. (1997). VRML 2.0 Source Book, 2nd Ed., Wiley, New York.

Beyerlein, S., et al. (2010). "Formulating learning outcomes based on core concepts for the introductory transportation engineering course." 89th Annual Meeting Compendium of Papers, Transportation Research Board, Washington, DC

Bill, A., et al. (2011). "Development of knowledge tables and learning outcomes for an introductory course in transportation engineering." Transportation Research Record 2211, Transportation Research Board, Washington, DC, 27-35.

Chen, W., and Levinson, D. (2006). "Effectiveness of learning transportation network growth through simulation." J. Prof. Issues Eng. Educ. Pract., 132(1), 29-41.

Helbing, D., Hennecke, A., Shvetsov, V., and Treiber, M. (2002). "Microand macro-simulation of freeway traffic." Math. Comput. Model., 35(5/6), 517-547.

ITS Institute. (2012). HumanFirst, University of Minnesota. 〈http://www .humanfirst.umn.edu〉 (Sep. 12, 2012).

ITS International. (2006). "Interactive asset management has arrived." Software in road infrastructure, ITS International, Kent, UK.

Khisty, C. J. (1986). "Undergraduate transportation engineering education." Transportation Research Record 1101, Transportation Research Board, Washington, DC, 1-3.

Kyte, M. (2009). "What should undergraduate civil engineering students know about transportation engineering?" ITE J., 79(5), 26-29.

Kyte, M., Abdel-Rahim, A., and Lines, M. (2003). "Traffic signal operations education through hands-on experience: Lessons learned from a workshop prototype." Transportation Research Record 1848, Transportation Research Board, Washington, DC, 50-56.

Liao, C. F., Glick, D. B., Haag, S., and Baas, G. (2010). "Development and deployment of a traffic control game integrated with traffic engineering curriculum for teaching high school students." 89th Annual Meeting (CD-ROM), Transportation Research Board, Washington, DC.

Liao, C. F., Liu, H. X., and Levinson, D. M. (2009). "Engaging undergraduate students in transportation studies through simulating transportation for realistic engineering education and training (STREET)." Transportation Research Record 2109, Transportation Research Board, Washington, DC, 12-21.

Liao, C. F., Morris, T., and Donath, M. (2006). "Development of an Internet-based traffic simulation framework for transportation education and training." 85th Annual Meeting (CD-ROM), Transportation Research Board, Washington, DC.

Mannering, F. L., Kilareski, W. P., and Washburn, S. S. (2005). Principles of highway engineering and traffic analysis, 3rd Ed., Wiley, New York.

Minnesota Traffic Observatory (MTO), Univ. of Minnesota, and ITS Institute. (2008). ROAD user's manual, 〈http://street.umn.edu/Road/ javahelp/roadWebMain.html) (Dec., 2012).

Pantelidis, V. S. (1995). "Reasons to use virtual reality in education." VR Schools, 1(1), 9.

STREET. (2012). 〈http://www.street.umn.edu/〉 (Dec., 2012).

Treiber, M. (2010). Microsimulation of road traffic flow. 〈http://www .mtreiber.de/MicroApplet/index.html〉 (Sep. 12, 2012).

Turochy, R. E. (2006). "Determining the content of the first course in transportation engineering." J. Prof. Issues Eng. Educ. Pract., 132(3), 200-203.

Zhu, S., Xie, F., and Levinson, D. M. (2011). "Enhancing transportation education through on-line simulation using an agent-based demand and assignment model.” J. Prof. Issues Eng. Educ. Pract., 137(1), 38-45. 